\title{
Prognostic value of blood gas analyses in patients with idiopathic pulmonary arterial hypertension
}

\author{
M.M. Hoeper, M.W. Pletz, H. Golpon and T. Welte
}

ABSTRACT: Blood gas abnormalities in patients with idiopathic pulmonary arterial hypertension (IPAH) may be related to disease severity and prognosis.

The present authors performed a 12-yr retrospective analysis assessing arterialised capillary blood gases, haemodynamics, exercise variables and survival in 101 patients with IPAH.

At baseline, arterial oxygen tension $\left(\mathrm{Pa}, \mathrm{O}_{2}\right)$ and carbon dioxide arterial tension $\left(\mathrm{Pa}, \mathrm{CO}_{2}\right)$ were $9.17 \pm 1.86$ and $4.25 \pm 0.532 \mathrm{kPa}$, respectively. While $\mathrm{Pa}_{\mathrm{a}} \mathrm{O}_{2}$ was not associated with survival, a low $\mathrm{Pa}, \mathrm{CO}_{2}$ was a strong and independent prognostic marker. When patients were divided according to a baseline $\mathrm{Pa}, \mathrm{CO}_{2}$ value above or below $4.25 \mathrm{kPa}$, a cut-off value determined by receiver operating characteristics analysis, survival rates were 98 and $86 \%$ at 1 yr, 82 and $69 \%$ at 2 years, 80 and $51 \%$ at $3 \mathrm{yrs}, 77$ and $41 \%$ at $5 \mathrm{yrs}$, and 65 and $12 \%$ at $8 \mathrm{yrs}$, respectively. $\mathrm{Pa}_{\mathrm{a}} \mathrm{CO}_{2}$ after 3 months of medical therapy was strongly associated with survival. Hypocapnia at rest and during exercise correlated with low cardiac output, low peak oxygen uptake and reduced ventilatory efficacy. Multiple regression analysis revealed that 6-min walking distance, right atrial pressure and $\mathrm{Pa}_{\mathrm{a}} \mathrm{CO}_{2}$ were independently associated with survival.

In patients with idiopathic pulmonary arterial hypertension, hypocapnia (carbon dioxide arterial tension $<4.25 \mathrm{kPa}$ ) is an independent marker of mortality.

KEYWORDS: Blood gases, carbon dioxide, hyperventilation, hypoxia, pulmonary hypertension
For these reasons, a 12-yr retrospective study was conducted in patients with IPAH in order to assess relationships between blood gases at rest and during exercise, haemodynamic parameters, variables obtained during cardiopulmonary exercise testing (CPET) and survival.

\section{METHODS}

Hospital charts from all patients with IPAH who were seen for the first time at the Hannover Medical School (Hannover, Germany) between January 1995 and December 2005 were reviewed. The follow-up period for survival analysis ended on April 30, 2006. Eligibility criteria for analysis were: 1) a diagnosis of IPAH according to current classification; 2) aged 18-75 yrs; and 3) normal or near normal results of pulmonary function testing, as defined by a vital capacity (VC) $>70 \%$ predicted and a forced expiratory volume in one second/VC ratio $>50 \%$. Patients with a persistent foramen ovale, as evident from echo studies or from characteristic findings during cardiopulmonary exercise testing [3], were
AFFILIATIONS

Hannover Medical School, Hannover, Germany.

CORRESPONDENCE

M.M. Hoeper Dept of Respiratory Medicine Hannover Medical School Carl-Neuberg-Str. 1 30625 Hannover Germany Fax: 495115328536 E-mail: hoeper.marius@mhhannover.de

Received:

October 152006

Accepted after revision: January 152007

SUPPORT STATEMENT

None of the authors received financial or other support for the present study.

STATEMENT OF INTEREST None declared.

European Respiratory Journa Print ISSN 0903-1936 Online ISSN 1399-3003 
excluded, as were patients with profound anaemia (haemoglobin level $<10 \mathrm{~g} \cdot \mathrm{dL}^{-1}$ ).

Patients were regularly seen 3 months after their baseline evaluations and then in 1-6 month intervals, or whenever clinically indicated. Right heart catheterisations were performed at the initial diagnostic work-up in all patients and at irregular follow-up intervals based on clinical situation. Cardiac output was assessed by the thermo-dilution technique. Mixed venous blood gases were obtained from the distal (pulmonary arterial) opening of the Swan-Ganz catheter.

Pulmonary function testing was performed using standard technology. During each visit, arterialised capillary blood gases were obtained by experienced technicians from hyperaemisised earlobes after a resting period $\geqslant 10 \mathrm{~min}$ while patients were breathing room air. The alveolar-arterial oxygen tension difference $\left(\mathrm{PA}-\mathrm{a}, \mathrm{O}_{2}\right)$ was estimated using the following equation:

$$
P A-a, \mathrm{O}_{2}=150-\left(P a, \mathrm{O}_{2}+P \mathrm{a}, \mathrm{CO}_{2} / 0.8\right)
$$

In 2001, CPET was introduced at the Hannover Medical School as a standard follow-up procedure for patients with IPAH. CPET was performed on a cycle ergometer, as described elsewhere [4]. Briefly, after a resting period of $3 \mathrm{~min}$, patients were asked to cycle at $60-70 \mathrm{rpm}$ while the work rate was increased by $5-15 \mathrm{~W} \cdot \mathrm{min}^{-1}$ until maximum tolerance. Gas exchange measurements were performed continuously (Oxycon Champion; Jaeger, Wuerzburg, Germany). Cardiac frequency, pulse oxymetry, 12-lead ECG and blood pressure were monitored and recorded. Arterialised capillary blood gases were obtained at rest and at the anaerobic threshold (AT) using the same technique as described previously.

Minute ventilation $\left(V^{\prime} \mathrm{E}\right)$, oxygen uptake $\left(V^{\prime} \mathrm{O}_{2}\right)$, carbon dioxide output $\left(V^{\prime} \mathrm{CO}_{2}\right)$, end-tidal carbon dioxide tension $\left(\mathrm{ET}-P \mathrm{CO}_{2}\right)$ and dead space/tidal volume $(V \mathrm{D} / V \mathrm{~T})$ ratio were measured breath by breath, interpolated second by second and averaged over 10 -s intervals. AT was defined as the $V^{\prime} \mathrm{O}_{2}$ at the point when the respiratory exchange ratio reached 1.0. Ventilatory efficacy was expressed as the ratio between $V^{\prime} \mathrm{E}$ and $V^{\prime} \mathrm{CO}_{2}$ at rest $\left(V^{\prime} \mathrm{E} /\right.$ $V^{\prime} \mathrm{CO}_{2}$,rest $)$ and at $\mathrm{AT}\left(V^{\prime} \mathrm{E} / V^{\prime} \mathrm{CO}_{2}, \mathrm{AT}\right)$.

Since the present study comprised a 12-yr period, medical therapies differed substantially among patients depending on their clinical needs and the time when they were treated. Only four patients were successfully treated solely with calcium channel blockers. The other patients received treatments that were available in the respective periods, including inhaled iloprost, beraprost, s.c. treprostinil, bosentan, sildenafil, or i.v. iloprost, either as monotherapy or in various combinations. The criteria for therapeutic decision making in recent years have been described in detail elsewhere [5].

The study protocol was approved by the local institutional review board. In accordance with German regulations, informed consent was waived due to the retrospective nature of the present study.

\section{Statistical analysis}

All data are shown as mean \pm SD. The end-point of the study was all-cause mortality or lung or heart-lung transplantation. Survival rates at different time-points were estimated using the
Kaplan-Meier method and any differences between groups were evaluated with a stratified log-rank test. Changes in individual variables from rest to exercise were compared using Wilcoxon's signed rank test. Pearson's correlation analysis was used to assess relationships between blood gases, haemodynamics, 6-min walking distance (6MWD) and variables obtained during cardiopulmonary exercise testing.

In order to identify the $\mathrm{Pa}_{1}, \mathrm{CO}_{2}$ value with the best predictive value for survival, receiver operating characteristic (ROC) curves for survival at 2 yrs were drawn and the areas under the curves (AUC) calculated. The cut-off level that resulted in the highest product of sensitivity and specificity was considered the optimal $\mathrm{Pa}_{\mathrm{a}} \mathrm{CO}_{2}$ value for predicting survival. ROC curves were also drawn for other markers of potential prognostic importance, such as 6MWD and certain haemodynamic variables.

Multiple logistic regression analysis was performed to assess the association between variables and the combined end-point of all-cause mortality and lung or heart-lung transplantation. Odds ratios (ORs) and 95\% confidence intervals (CIs) for risk factors are given. CPET variables were not included in the survival analyses since this tool was introduced relatively late in the course of the present study. A p-value $<0.05$ was considered statistically significant.

\section{RESULTS}

The present authors identified 101 consecutive patients with IPAH fulfilling the inclusion and exclusion criteria of the current study. In general, these patients suffered from severe pulmonary hypertension at baseline with a mean 6MWD of $305 \mathrm{~m}$ and a mean pulmonary vascular resistance (PVR) of $1,157 \mathrm{dyn} \cdot \mathrm{s} \cdot \mathrm{cm}^{-5}$, and the vast majority presented in functional class III or IV. A summary of the patients' baseline characteristics is shown in table 1 .

During the observation period, 38 patients died and three underwent lung or heart-lung transplantation, resulting in a total number of 41 events. The rates for survival without transplantation were $93 \%$ at $1 \mathrm{yr}, 77 \%$ at $2 \mathrm{yrs}, 67 \%$ at $3 \mathrm{yrs}$, $60 \%$ at 5 yrs and $41 \%$ at 8 yrs.

\section{Correlations between blood gases at rest, haemodynamics and 6MWD at baseline}

Blood gas analysis at baseline showed a mean $\mathrm{Pa}_{1} \mathrm{O}_{2}$ of $9.17 \pm 1.86 \mathrm{kPa}$ and a mean $\mathrm{Pa}, \mathrm{CO}_{2}$ of $4.25 \pm 0.53 \mathrm{kPa}$. The mean arterial oxygen saturation was $93 \pm 4 \%$. Further variables are shown in table 1.

Neither $\mathrm{Pa}, \mathrm{O}_{2}$ nor $\mathrm{Pa}_{\mathrm{a}} \mathrm{CO}_{2}$ correlated with mean pulmonary arterial pressure (mPAP) or PVR. As shown in table 2, there was a weak but statistically significant correlation between $\mathrm{Pa}_{1} \mathrm{O}_{2}$ and 6MWD $(\mathrm{r}=0.298, \mathrm{p}=0.001)$ and between $\mathrm{Pa}, \mathrm{O}_{2}$ and the mixed venous oxygen saturation $\left(S \mathrm{~V}, \mathrm{O}_{2} ; \mathrm{r}=0.277, \mathrm{p}=0.026\right)$. A significant inverse correlation was also observed between $\mathrm{Pa}_{\mathrm{a}} \mathrm{O}_{2}$ and the right atrial pressure (RAP; $r=-0.269, p=0.007)$. The change in $\mathrm{SV}, \mathrm{O}_{2}$ during the course of the disease did not correlate with the change in $\mathrm{Pa}_{\mathrm{a}} \mathrm{O}_{2}(\mathrm{r}=0.136, \mathrm{p}=0.158)$.

$\mathrm{Pa}_{\mathrm{a}} \mathrm{CO}_{2}$ was not correlated with $6 \mathrm{MWD}$ or RAP and showed weak but significant correlations with the cardiac index $(\mathrm{r}=0.235, \mathrm{p}=0.019)$ and $\mathrm{SV}, \mathrm{O}_{2}(\mathrm{r}=0.226, \mathrm{p}=0.026)$, suggesting 


\begin{tabular}{|c|c|c|}
\hline \multirow[t]{2}{*}{ TABLE 1} & \multicolumn{2}{|c|}{$\begin{array}{l}\text { Summary of baseline demographics, } \\
\text { haemodynamics, pulmonary function results, } \\
\text { blood gases at rest and variables obtained } \\
\text { during cardiopulmonary function testing }\end{array}$} \\
\hline & Study population & CPET subgroup \\
\hline Subjects $n$ & 101 & 53 \\
\hline Female/male & $76 / 25$ & $43 / 10$ \\
\hline \multicolumn{3}{|l|}{ NYHA } \\
\hline$\|$ & 3 & 2 \\
\hline III & 78 & 44 \\
\hline IV & 20 & 7 \\
\hline Age yrs & $48 \pm 15$ & $47 \pm 14$ \\
\hline 6MWD m & $305 \pm 118$ & $334 \pm 100$ \\
\hline RAP mmHg & $9 \pm 6$ & $9 \pm 6$ \\
\hline mPAP $\mathrm{mmHg}$ & $56 \pm 13$ & $55 \pm 14$ \\
\hline Cardiac output L. $\min ^{-1}$ & $3.7 \pm 1.1$ & $3.7 \pm 1.1$ \\
\hline Cardiac index $L \cdot \min ^{-1} \cdot m^{-2}$ & $2.0 \pm 0.5$ & $2.0 \pm 0.5$ \\
\hline PVR dyn $\cdot \mathbf{s} \cdot \mathrm{cm}^{-5}$ & $1157 \pm 492$ & $1142 \pm 465$ \\
\hline $\mathrm{Sv}, \mathrm{O}_{2} \%$ & $61 \pm 9$ & $60 \pm 10$ \\
\hline FVC \% pred & $89 \pm 13$ & $93 \pm 14$ \\
\hline $\mathrm{FEV}_{1} / \mathrm{VC} \%$ & $75 \pm 11$ & $75 \pm 11$ \\
\hline$D\llcorner, \mathrm{CO} \%$ pred & $64 \pm 23$ & $65 \pm 25$ \\
\hline Peak $V^{\prime} \mathrm{O}_{2} \mathrm{~mL} \cdot \mathrm{kg}^{-1} \cdot \mathrm{min}^{-1}$ & NA & $13.4 \pm 3.6$ \\
\hline $\mathrm{O}_{2} / f \mathrm{c} \mathrm{mL}$ & NA & $7.1 \pm 2.1$ \\
\hline$V^{\prime} \mathrm{E} / V^{\prime} \mathrm{CO}_{2}, \mathrm{AT}$ & NA & $48 \pm 15$ \\
\hline \multicolumn{3}{|l|}{$\mathrm{ET}-\mathrm{PCO}_{2}$} \\
\hline At rest & NA & $27 \pm 5$ \\
\hline At AT & NA & $25 \pm 7$ \\
\hline \multicolumn{3}{|l|}{$V_{D} / V_{T}$} \\
\hline At rest & NA & $16 \pm 6$ \\
\hline At AT & NA & $18 \pm 4$ \\
\hline \multicolumn{3}{|l|}{$\mathrm{Pa}, \mathrm{O}_{2} \mathrm{mmHg}$} \\
\hline At rest & $69 \pm 14$ & $69 \pm 12$ \\
\hline At AT & NA & $65 \pm 14$ \\
\hline \multicolumn{3}{|l|}{${\mathrm{Pa}, \mathrm{CO}_{2} \mathrm{mmHg}}$} \\
\hline At rest & $32 \pm 4$ & $33 \pm 4$ \\
\hline At AT & NA & $32 \pm 5$ \\
\hline \multicolumn{3}{|l|}{$\mathrm{pH}$} \\
\hline At rest & $7.46 \pm 0.03$ & $7.46 \pm 0.03$ \\
\hline At AT & NA & $7.44 \pm 0.04$ \\
\hline \multicolumn{3}{|l|}{$\mathrm{HCO}_{3}^{-}$} \\
\hline At rest & $22.6 \pm 2.7$ & $22.8 \pm 2.8$ \\
\hline At AT & NA & $20.8 \pm 2.9$ \\
\hline
\end{tabular}

Data are presented as mean $\pm S D$, unless otherwise stated. CPET: cardiopulmonary exercise testing; NYHA: New York Heart Association; 6MWD: 6-min walking distance; RAP: right atrial pressure; mPAP: mean pulmonary arteria pressure; PVR: pulmonary vascular resistance; $\mathrm{SV}_{1} \mathrm{O}_{2}$ : mixed venous oxygen saturation; FVC: forced vital capacity; \% pred: \% predicted; FEV1: forced expiratory volume in one second; $\mathrm{VC}$ : vital capacity; $\mathrm{DL}, \mathrm{CO}$ : diffusing capacity of the lungs for carbon monoxide; $V^{\prime} \mathrm{O}_{2}$ : oxygen uptake; $\mathrm{O}_{2} / \mathrm{fc}$ : oxygen pulse, where $f C$ is the cardiac frequency; $V^{\prime} E / V^{\prime} \mathrm{CO}_{2}, \mathrm{AT}$ : ventilatory efficacy expressed as the ratio between minute ventilation and carbon dioxide output at the anaerobic threshold (AT); ET-PCO 2 : end-tidal carbon dioxide tension; VD/VT: dead space/ tidal volume ratio; $\mathrm{Pa}_{1} \mathrm{O}_{2}$ : arterial oxygen tension; $\mathrm{Pa}_{1} \mathrm{CO}_{2}$ : carbon dioxide arterial tension; NA: not assessed. $1 \mathrm{mmHg}=0.133 \mathrm{kPa}$.

\begin{tabular}{|c|c|c|c|c|c|c|}
\hline \multirow[t]{2}{*}{ TABLE 2} & \multicolumn{6}{|c|}{$\begin{array}{l}\text { Correlations between blood gases at rest, } \\
\text { haemodynamics and 6-min walking distance } \\
(6 \mathrm{MWD})\end{array}$} \\
\hline & 6MWD & RAP & mPAP & $\begin{array}{c}\text { Cardiac } \\
\text { index }\end{array}$ & PVR & $\mathrm{Sv}, \mathrm{O}_{2}$ \\
\hline \multicolumn{7}{|l|}{$\mathrm{Pa}, \mathrm{O}_{2}$} \\
\hline . & 0.298 & -0.269 & 0.108 & 0.008 & 0.161 & 0.227 \\
\hline $\mathrm{p}$-value & 0.001 & 0.007 & NS & NS & NS & 0.026 \\
\hline \multicolumn{7}{|l|}{${\mathrm{Pa}, \mathrm{CO}_{2}}$} \\
\hline r & 0.104 & -0.054 & -0.049 & 0.235 & -0.185 & 0.226 \\
\hline$p$-value & NS & NS & NS & 0.019 & NS & 0.026 \\
\hline
\end{tabular}

RAP: right atrial pressure; mPAP: mean pulmonary arterial pressure; PVR pulmonary vascular resistance; $\mathrm{SV}, \mathrm{O}_{2}$ : mixed venous oxygen saturation $\mathrm{Pa}, \mathrm{O}_{2}$ : arterial oxygen tension; $\mathrm{Pa}_{\mathrm{a}} \mathrm{CO}_{2}$ : carbon dioxide arterial tension NS: nonsignificant.

that the degree of hyperventilation was partly related to reduced cardiac output. In accordance, the change in $\mathrm{Pa}, \mathrm{CO}_{2}$ during the course of the disease correlated significantly with the change in cardiac index $(\mathrm{r}=0.362, \mathrm{p}<0.001)$.

\section{Correlations between blood gases at rest and during exercise and CPET}

As CPET was introduced in the present programme in 2001, only 53 patients had exercise tests performed at baseline. In this subpopulation, exercise caused a mild drop in $\mathrm{Pa}_{2} \mathrm{O}_{2}$ from $9.17 \pm 1.59 \mathrm{kPa}$ at rest to $8.64 \pm 1.86 \mathrm{kPa}$ at $\mathrm{AT}(\mathrm{p}=0.004)$, while $\mathrm{Pa}, \mathrm{CO}_{2}$ remained virtually unchanged (table 1 ). $\mathrm{HCO}_{3}{ }^{-}$decreased from $22.8 \pm 2.8 \mathrm{mmol} \cdot \mathrm{L}^{-1}$ at rest to $20.8 \pm 2.9 \mathrm{mmol} \cdot \mathrm{L}^{-1}$ at $\mathrm{AT}$ $(\mathrm{p}<0.001)$ and the $\mathrm{pH}$ decreased from $7.46 \pm 0.03$ to $7.44 \pm 0.04$ $(\mathrm{p}<0.001)$. ET- $\mathrm{PCO}_{2}$ fell from $3.59 \pm 0.66 \mathrm{kPa}$ at rest to $3.32 \pm 0.66 \mathrm{kPa}$ at $\mathrm{AT}(\mathrm{p}=0.017)$ and the $V \mathrm{D} / V \mathrm{~T}$ ratio increased from $16 \pm 6$ to $18 \pm 4(p=0.004)$. There were no significant correlations at rest or during exercise between either $\mathrm{Pa}_{\mathrm{a}} \mathrm{CO}_{2}$ or ET- $P \mathrm{CO}_{2}$ and the $V \mathrm{D} / V \mathrm{~T}$ ratio. In addition, there was no correlation between $\mathrm{Pa}, \mathrm{O}_{2}$ and $\mathrm{Pa}, \mathrm{CO}_{2}$ at rest and during exercise but a significant correlation was observed between $\mathrm{Pa}_{\mathrm{a}} \mathrm{O}_{2}$ at rest and ET- $P \mathrm{CO}_{2}$ at rest $(\mathrm{r}=0.439, \mathrm{p}<0.001)$, as well as between $\mathrm{Pa}, \mathrm{O}_{2}$ at AT and ET-PCO $\mathrm{CO}_{2}$ at AT $(\mathrm{r}=0,632, \mathrm{p}<0.001)$, probably reflecting, at least partly, effects of ventilation/perfusion abnormalities.

As shown in table $3, \mathrm{~Pa}_{\mathrm{a}} \mathrm{O}_{2}$ at rest, but not $\mathrm{Pa}_{\mathrm{a}}, \mathrm{CO}_{2}$ at rest, showed a weak but significant correlation with the peak $V^{\prime} \mathrm{O}_{2}(\mathrm{r}=0.303$, $\mathrm{p}=0.03$ ). In contrast, there were stronger correlations between the peak $V^{\prime} \mathrm{O}_{2}$ and both $\mathrm{Pa}, \mathrm{O}_{2}$ and $\mathrm{Pa}_{1}, \mathrm{CO}_{2}$ at AT $(\mathrm{r}=0.404$, $\mathrm{p}=0.005$ and $\mathrm{r}=0.479, \mathrm{p}<0.001$, respectively). There were also significant inverse correlations between peak $V^{\prime} \mathrm{O}_{2}$ and ventilatory efficacy at rest as well as during exercise (table 3), supporting the hypothesis that ventilatory efficacy is inversely related to cardiac output, i.e. pulmonary perfusion.

$V^{\prime} \mathrm{E} / V^{\prime} \mathrm{CO}_{2}, \mathrm{AT}$ showed significant inverse correlations with $\mathrm{Pa}, \mathrm{O}_{2}$ and $\mathrm{Pa}, \mathrm{CO}_{2}$ at rest (table 3 ) and an even stronger inverse correlation with the $\mathrm{Pa}_{\mathrm{a}} \mathrm{O}_{2}$ at AT $(\mathrm{r}=-0.729, \mathrm{p}<0.001)$.

Relationship between blood gases at baseline and survival The baseline $\mathrm{Pa}_{1} \mathrm{O}_{2}$ at rest had no significant impact on survival. When patients were divided according to a baseline $\mathrm{Pa}_{1} \mathrm{O}_{2}$ value 


\begin{tabular}{|c|c|c|c|c|c|}
\hline \multirow[t]{2}{*}{ TABLE : } & \multicolumn{5}{|c|}{$\begin{array}{l}\text { Correlations between blood gases and variables } \\
\text { obtained during cardiopulmonary exercise } \\
\text { testing }\end{array}$} \\
\hline & Peak V'O $\mathrm{O}_{2}$ & $V^{\prime} \mathrm{E} / \mathrm{V}^{\prime} \mathrm{CO}_{2}$, rest & $V^{\prime} \mathrm{E} / V^{\prime} \mathrm{CO}_{2}, \mathrm{AT}$ & $\mathrm{Pa}, \mathrm{O}_{2}, \mathrm{AT}$ & $\mathrm{Pa}, \mathrm{CO}_{2}, \mathrm{AT}$ \\
\hline \multicolumn{6}{|l|}{$\begin{array}{c}{\mathrm{Pa}, \mathrm{O}_{2}}_{\text {at }} \\
\text { rest }\end{array}$} \\
\hline$r$ & 0.303 & -0.367 & -0.431 & 0.682 & 0.132 \\
\hline$p$-value & 0.03 & 0.008 & 0.002 & $<0.001$ & NS \\
\hline \multicolumn{6}{|l|}{$\begin{array}{c}\mathrm{Pa}, \mathrm{CO}_{2} \text { at } \\
\text { rest }\end{array}$} \\
\hline$r$ & 0.191 & -0.250 & -0.389 & 0.137 & 0.659 \\
\hline $\mathrm{p}$-value & NS & NS & 0.006 & NS & $\leqslant 0.001$ \\
\hline \multicolumn{6}{|l|}{ Peak V'O $\mathrm{O}_{2}$} \\
\hline r & NA & -0.343 & -0.541 & 0.404 & 0.479 \\
\hline$p$-value & & 0.015 & $<0.001$ & 0.005 & $<0.001$ \\
\hline
\end{tabular}

$V^{\prime} \mathrm{O}_{2}$ : oxygen uptake; $V^{\prime} E / N^{\prime} \mathrm{CO}_{2}$ : ventilatory efficacy expressed as the ratio between minute ventilation and carbon dioxide output; AT: anaerobic threshold; $\mathrm{Pa}_{\mathrm{a}} \mathrm{O}_{2}$ : arterial oxygen tension; $\mathrm{Pa}_{\mathrm{a}} \mathrm{CO}_{2}$ : carbon dioxide arterial tension; NS: nonsignificant; NA: not assessed.

above or below the median of $67.5 \mathrm{mmHg}$, survival rates were 98 and $84 \%$ at $1 \mathrm{yr}, 79$ and $73 \%$ at $2 \mathrm{yrs}, 70$ and $63 \%$ at $3 \mathrm{yrs}, 58$ and $57 \%$ at $5 \mathrm{yrs}$, and 58 and $16 \%$ at 8 yrs, a difference that did not reach statistical significance ( $\mathrm{p}=0.18$ by log-rank analysis; fig. 1 ). Similar results were obtained when $\mathrm{PA}-\mathrm{a}, \mathrm{O}_{2}$, rather than $\mathrm{Pa}_{\mathrm{a}} \mathrm{O}_{2}$, was examined. The median was $5.58 \mathrm{kPa}$ and no significant survival differences were observed between patients who had a $P A-a, \mathrm{O}_{2}$ above or below that value $(\mathrm{p}=0.115)$.

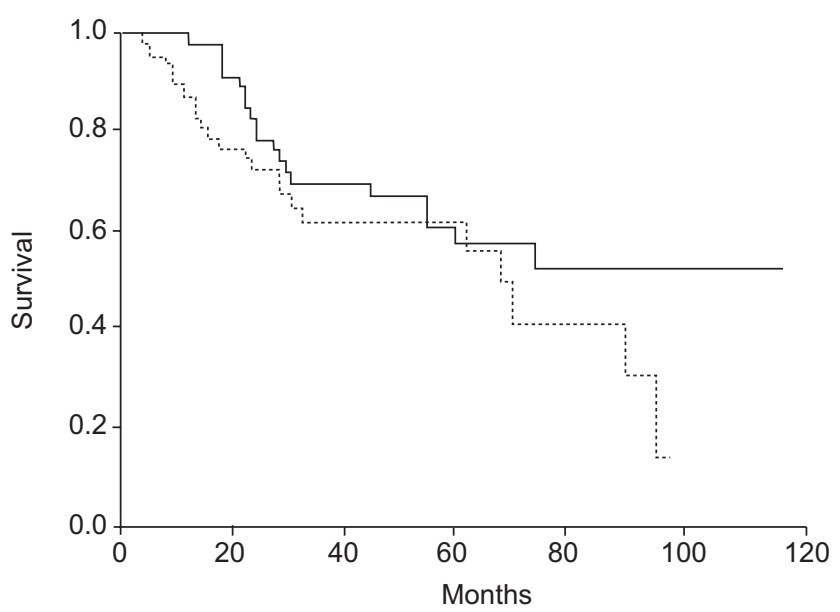

FIGURE 1. Impact of baseline arterial oxygen tension $\left(\mathrm{Pa}_{\mathrm{a}} \mathrm{O}_{2}\right)$ on survival in patients with idiopathic pulmonary arterial hypertension (IPAH). Kaplan-Meier survival estimates of 101 patients with IPAH according to their baseline $\mathrm{Pa}_{\mathrm{a}} \mathrm{O}_{2}$. $\mathrm{Pa}_{1} \mathrm{O}_{2} \geqslant 8.97 \mathrm{kPa} ; \cdots \cdots . . . \mathrm{Pa}_{\mathrm{a}} \mathrm{O}_{2}<8.97 \mathrm{kPa}$. For a $\mathrm{Pa}_{1} \mathrm{O}_{2} \geqslant 8.97 \mathrm{kPa}$, the number of subjects at risk was $51,47,31,18,14,12$ and 5 for the baseline, 20, 40, 60, 80, 100 and 120 months, respectively. For a $\mathrm{Pa}_{\mathrm{a}} \mathrm{O}_{2}<8.97 \mathrm{kPa}$, the number of subjects at risk was 50, 38, 25, 18, 6, 2 and 0 for the baseline, 20, 40, 60, 80, 100 and 120 months, respectively. $p=0.18$
In contrast, baseline $\mathrm{Pa}_{\mathrm{a}} \mathrm{CO}_{2}$ at rest had a much stronger impact on survival. ROC analysis did identify a $\mathrm{Pa}_{1} \mathrm{CO}_{2}$ of $4.25 \mathrm{kPa}$ as the optimal cut-off level with a sensitivity of 0.73 and a specificity of 0.66 to predict survival at 2 yrs (AUC (95\% CI) $0.70(0.59-0.81) ; \mathrm{p}<0.001)$. This cut-off point was identical to the median value of $P \mathrm{a}, \mathrm{CO}_{2}$ in the present patient population. When patients were divided according to a baseline $\mathrm{Pa}_{3} \mathrm{CO}_{2}$ value above or below $4.25 \mathrm{kPa}$, survival rates were 98 and $86 \%$ at $1 \mathrm{yr}, 82$ and $69 \%$ at 2 yrs, 80 and $51 \%$ at 3 yrs, 77 and $41 \%$ at $5 \mathrm{yrs}$, and 65 and $12 \%$ at $8 \mathrm{yrs}$, a difference that was of high statistical significance $(p<0.001$ by log-rank analysis; fig. 2$)$.

Blood gases obtained after 3 months of medical treatment gave similar results. $\mathrm{Pa}, \mathrm{O}_{2}$ after 3 months was not significantly associated with survival (table 4). $\mathrm{Pa}_{1}, \mathrm{CO}_{2}$ after 3 months of therapy, however, appeared to be even more strongly associated with survival than baseline values. In this case the cut-off value was $4.32 \mathrm{kPa}$. Patients with $\mathrm{Pa}_{\mathrm{a}} \mathrm{CO}_{2}$ values $>4.32 \mathrm{kPa}$ had survival rates at 1, 2, 3, 5 and 8 yrs of 95, 86, 83,83 and $78 \%$, respectively, whereas patients with $\mathrm{Pa}_{\mathrm{a}} \mathrm{CO}_{2}$ values $<4.32 \mathrm{kPa}$ had survival rates at $1,2,3,5$ and 8 yrs of 88 , $70,57,46$ and $15 \%$, respectively $(\mathrm{p}<0.001$ by log-rank analysis; fig. 3).

Univariate logistic regression analysis revealed that $6 \mathrm{MWD}$, RAP, cardiac output, PVR, $\mathrm{SV}, \mathrm{O}_{2}$ and $\mathrm{Pa}_{\mathrm{a}} \mathrm{CO}_{2}$ at baseline, as well as after 3 months of therapy, were associated with survival (table 4). This was not the case for mPAP and $\mathrm{Pa}_{\mathrm{a}} \mathrm{O}_{2}$. Multiple logistic regression analysis revealed that only 6MWD, RAP and $\mathrm{Pa}_{\mathrm{a}} \mathrm{CO}_{2}$ both at baseline and after 3 months were independently associated with mortality (table 5).

Comparison of several variables as predictors of mortality As shown in figure 4, ROC analysis demonstrated that the prognostic value of a low $\mathrm{Pa}, \mathrm{CO}_{2}$ at baseline (AUC (95\% CI) 0.70

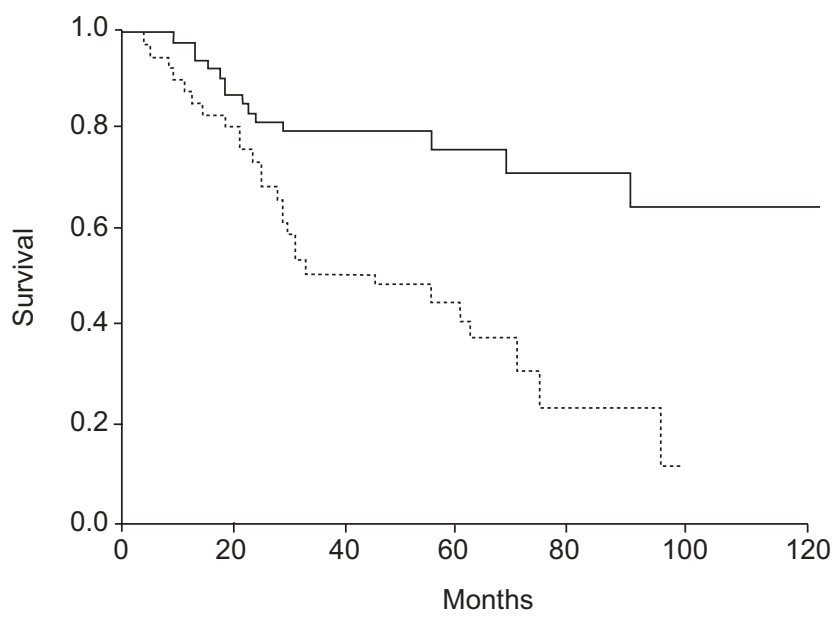

FIGURE 2. Impact of baseline carbon dioxide arterial tension $\left(\mathrm{Pa}_{\mathrm{a}} \mathrm{CO}_{2}\right)$ on survival in patients with idiopathic pulmonary arterial hypertension (IPAH). KaplanMeier survival estimates of 101 patients with IPAH according to their baseline $P a, C_{2}$. - $: P a, C_{2} \geqslant 4.25 \mathrm{kPa} ; \cdots \cdots \cdot: P a_{1} C_{2}<4.25 \mathrm{kPa}$. For a $P \mathrm{a}_{1} \mathrm{CO}_{2} \geqslant 4.25 \mathrm{kPa}$, the number of subjects at risk was $57,51,35,16,13,12$ and 5 for the baseline, 20, $40,60,80,100$ and 120 months, respectively. For a $\mathrm{Pa}_{1} \mathrm{CO}_{2}<4.25 \mathrm{kPa}$, the number of subjects at risk was 44, 34, 21, 12, 4, 2 and 0 for the baseline, 20, 40, 60, 80, 100 and 120 months, respectively. $p<0.001$. 


\begin{tabular}{|c|c|c|}
\hline TABLE 4 & $\begin{array}{l}\text { Parameters predictive of survi } \\
\text { analysis }\end{array}$ & variate \\
\hline $\begin{array}{l}\text { Independent } \\
\text { variable }\end{array}$ & OR $(95 \% \mathrm{Cl})$ & $\mathrm{p}$-value \\
\hline 6MWD & $1.007(1.003-1.011)$ & $<0.001$ \\
\hline RAP & $0.873(0.805-0.947)$ & 0.001 \\
\hline mPAP & $0.984(0.954-1.014)$ & 0.292 \\
\hline Cardiac index & $2.591(1.075-6.241)$ & 0.034 \\
\hline PVR & $0.999(0.998-1.000)$ & 0.040 \\
\hline $\mathrm{Sv}, \mathrm{O}_{2}$ & $1.057(1.007-1.109)$ & 0.025 \\
\hline \multicolumn{3}{|l|}{$\mathrm{Pa}, \mathrm{O}_{2}$} \\
\hline At baseline & $1.025(0.996-1.056)$ & 0.097 \\
\hline At 3 months & $1.020(0.991-1.049)$ & 0.176 \\
\hline \multicolumn{3}{|l|}{$\mathrm{Pa}, \mathrm{CO}_{2}$} \\
\hline At baseline & $1.191(1.058-1.341)$ & 0.004 \\
\hline At 3 months & $1.449(1.242-1.690)$ & $<0.001$ \\
\hline
\end{tabular}

OR: odds ratio; Cl: confidence interval; 6MWD: 6-min walking distance; RAP: right atrial pressure; mPAP: mean pulmonary arterial pressure; PVR: pulmonary vascular resistance; $\mathrm{SV}_{\mathrm{O}_{2}}$ : mixed venous oxygen saturation; $\mathrm{Pa}, \mathrm{O}_{2}$ : arterial oxygen tension; $\mathrm{Pa}_{1} \mathrm{CO}_{2}$ : carbon dioxide arterial tension.

$(0.59-0.81) ; \mathrm{p}<0.001)$ was similar to that of 6MWD (0.79 (0.69$0.87) ; \mathrm{p}<0.001)$ and RAP $(0.29(0.18-0.40) ; \mathrm{p}<0.001)$, and better than mPAP $(0.41(0.29-0.53) ; \mathrm{p}=0.138)$ or the cardiac index (0.64 (0.53-0.76); $\mathrm{p}=0.021)$.

\section{DISCUSSION}

The present study confirmed that mild hypoxaemia and mildto-moderate hypocapnia at rest and during exercise are common findings in patients with IPAH. Neither hypoxaemia nor hypocapnia were related to the magnitude of the pulmonary artery pressure. There were significant but weak correlations between $\mathrm{Pa}_{2} \mathrm{O}_{2}$ at rest and 6MWD, and RAP and $\mathrm{SV}, \mathrm{O}_{2}$, respectively. $\mathrm{Pa}_{\mathrm{a}} \mathrm{CO}_{2}$ at rest correlated with cardiac index and $\mathrm{SV}, \mathrm{O}_{2}$. The most important finding of the present study, however, was the prognostic importance of a low $\mathrm{Pa}_{\mathrm{a}} \mathrm{CO}_{2}$ both at baseline and after 3 months of medical therapy in patients with IPAH. In contrast, $\mathrm{Pa}_{2} \mathrm{O}_{2}$ had no significant prognostic value.

Several questions arise from the present findings. What is the relationship between blood gases and exercise limitation in patients with IPAH? What is the pathophysiological explanation for chronic hypocapnia, or, in other words, why do patients with IPAH hyperventilate? And finally, why is hypocapnia a marker of a poor prognosis, even if the $P \mathrm{a}_{1} \mathrm{CO}_{2}$ levels were not closely related to other variables of prognostic importance?

\section{What is the relationship between blood gases and exercise limitation in patients with IPAH?}

The 6MWD correlated with both $\mathrm{Pa}_{\mathrm{a}} \mathrm{O}_{2}$ at rest $(\mathrm{r}=0.3, \mathrm{p}=0.001)$ and during exercise $(\mathrm{r}=0.68, \mathrm{p}<0.001)$. This was to be expected since the main exercise limiting factor in patients with IPAH is oxygen delivery, which is the product of cardiac output and arterial oxygen content.

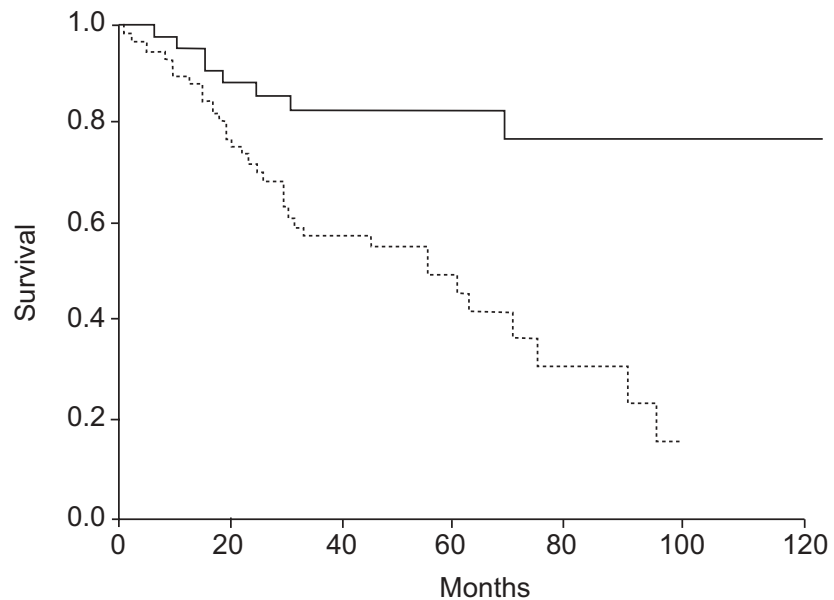

FIGURE 3. Impact of carbon dioxide arterial tension $\left(\mathrm{Pa}_{1} \mathrm{CO}_{2}\right)$ obtained after 3 months of therapy on survival in patients with idiopathic pulmonary arterial hypertension (IPAH). Kaplan-Meier survival estimates of 101 patients with IPAH according to their $\mathrm{Pa}, \mathrm{CO}_{2}$ after 3 months of therapy. $-\mathrm{Pa}, \mathrm{CO}_{2} \geqslant 4.32 \mathrm{kPa} ; \cdots \cdots$. $\mathrm{Pa}, \mathrm{CO}_{2}<4.32 \mathrm{kPa}$. For a $\mathrm{Pa}, \mathrm{CO}_{2} \geqslant 4.32 \mathrm{kPa}$, the number of subjects at risk was 57 , $51,35,16,13,12$ and 5 for the baseline, 20, 40, 60, 80, 100 and 120 months, respectively. For a $\mathrm{Pa}, \mathrm{CO}_{2}<4.32 \mathrm{kPa}$, the number of subjects at risk was $44,34,21$ $12,4,2$ and 0 for the baseline, 20, 40,60, 80, 100 and 120 months, respectively. $\mathrm{p}<0.001$.

The peak $V^{\prime} \mathrm{O}_{2}$ also correlated with the $\mathrm{Pa}, \mathrm{O}_{2}$ at rest but not with $\mathrm{Pa}_{1} \mathrm{CO}_{2}$ at rest, in accordance with what has been shown in patients with left heart failure [6]. However, when blood gases were obtained during exercise, both $\mathrm{Pa}_{1} \mathrm{O}_{2}$ at AT $(\mathrm{r}=0.404$, $\mathrm{p}=0.005)$ and $\mathrm{Pa}_{1} \mathrm{CO}_{2}$ at AT $(\mathrm{r}=0.479, \mathrm{p}<0.001)$ did correlate significantly with peak $V^{\prime} \mathrm{O}_{2}$. It is likely that both a higher $\mathrm{Pa}_{\mathrm{a}} \mathrm{O}_{2}$ and a higher $\mathrm{Pa}_{1} \mathrm{CO}_{2}$ during exercise are indicators of a more effective pulmonary perfusion $[7,8]$.

This concept is further supported by the rather strong inverse correlation between peak $V^{\prime} \mathrm{O}_{2}$ and $V^{\prime} \mathrm{E} / V^{\prime} \mathrm{CO}_{2}, \mathrm{AT} \quad(\mathrm{r}=-0.541$, $\mathrm{p}<0.001$ ). A very similar correlation between these variables has been reported previously in patients with IPAH [9] but also in patients with congestive left heart failure, where the $V^{\prime} \mathrm{E} / V^{\prime} \mathrm{CO}_{2}$ ratio is usually regarded as an indicator of pulmonary perfusion $[6,10]$.

Thus, exercise limitation was weakly related to $\mathrm{Pa}_{1} \mathrm{O}_{2}$ at rest but more closely so to blood gases obtained during exercise, i.e. both $\mathrm{Pa}, \mathrm{O}_{2}$ and $\mathrm{Pa}, \mathrm{CO}_{2}$ at AT. Since the patients under study had no relevant ventilatory impairment, there is reason to believe that better blood gases during exercise reflect better pulmonary blood flow, e.g. a higher cardiac output.

\section{Why do patients with IPAH hyperventilate?}

An elevated $V^{\prime} \mathrm{E} / V^{\prime} \mathrm{CO}_{2}$ ratio is not sufficient to explain a low $\mathrm{Pa}_{\mathrm{a}} \mathrm{CO}_{2}$. The $V^{\prime} \mathrm{E} / V^{\prime} \mathrm{CO}_{2}$ ratio, or ventilatory efficacy, describes the amount of ventilation needed to remove a given amount of $\mathrm{CO}_{2}$. Elevated $V^{\prime} \mathrm{E} / V^{\prime} \mathrm{CO}_{2}$ ratios and low ET- $\mathrm{PCO}_{2}$ values have been reported in patients with pulmonary hypertension [11, 12] and heart failure [13], and are explained by insufficient perfusion of the lungs, including its extreme variant, dead space ventilation. While this concept is well suited to explain why patients with pulmonary vascular disease need to breathe 


\begin{tabular}{|c|c|c|c|}
\hline TABLE 5 & \multicolumn{3}{|c|}{$\begin{array}{l}\text { Multiple logistic regression analysis with survival } \\
\text { as dependent variable }\end{array}$} \\
\hline \multicolumn{2}{|c|}{ Independent variable } & OR (95\% Cl) & p-value \\
\hline \multicolumn{2}{|l|}{ 6MWD } & $1.006(1.001-1.010)$ & 0.022 \\
\hline \multicolumn{2}{|l|}{ RAP } & $0.874(0.788-0.968)$ & 0.010 \\
\hline \multicolumn{2}{|c|}{ Cardiac index } & $1.041(0.340-3.185)$ & 0.944 \\
\hline \multicolumn{4}{|l|}{$\mathrm{Pa}, \mathrm{CO}_{2}$} \\
\hline \multicolumn{2}{|c|}{ At baseline } & $1.166(1.020-1.333)$ & 0.025 \\
\hline \multicolumn{2}{|c|}{ At 3 months } & $1.512(1.224-1.867)$ & $<0.001$ \\
\hline
\end{tabular}

OR: odds ratio; $\mathrm{Cl}$ : confidence interval; 6MWD: 6-min walking distance; RAP: right atrial pressure; $\mathrm{Pa}_{\mathrm{a}} \mathrm{CO}_{2}$ : carbon dioxide arterial tension.

more to maintain a physiological $P \mathrm{a}, \mathrm{CO}_{2}$, it does not explain why they hyperventilate, i.e. why their $\mathrm{Pa}_{1} \mathrm{CO}_{2}$ is reduced to sub-physiological levels, sometimes $<3.99 \mathrm{kPa}$.

Many lines of evidence suggest that hyperventilation is partly linked to a low cardiac output, i.e. low pulmonary perfusion. The correlation between cardiac output and $\mathrm{Pa}_{1} \mathrm{CO}_{2}$ at rest was weak but significant $(r=0.235, p=0.019)$, and strikingly similar to what has been reported in patients with left heart failure [14]. It is noteworthy that there was a stronger correlation between $\mathrm{Pa}_{1} \mathrm{CO}_{2}$ at AT and peak $V^{\prime} \mathrm{O}_{2}(\mathrm{r}=0.479, \mathrm{p}=0.005)$, the latter partly reflecting cardiac output during exercise. In addition, there was a highly significant inverse correlation between $P \mathrm{a}, \mathrm{CO}_{2}$ at $\mathrm{AT}$ and $V^{\prime} \mathrm{E} / V^{\prime} \mathrm{CO}_{2}, \mathrm{AT}(\mathrm{r}=-0.649, \mathrm{p}<0.001)$, a finding that has also been reported with similar numbers $(\mathrm{r}=-0.651)$ in patients with left heart failure [10, 15-17]. This indicates that ventilatory efficacy declines with hyperventilation. Finally, changes in $\mathrm{Pa}, \mathrm{CO}_{2}$ during the course of the disease were significantly correlated with changes in cardiac output. Thus, there is strong reason to assume that cardiac output (or oxygen delivery) is an important regulator of the ventilatory drive and an inadequately low cardiac output at rest or during exercise seems to be a potent ventilatory stimulus, regardless of the underlying condition.

\section{Why is hypocapnia an independent marker of a poor prognosis in patients with pulmonary arterial hypertension?} The available evidence suggests that hypocapnia reflects an increased ventilatory drive caused by several mechanisms, including low cardiac output, impaired $V^{\prime} \mathrm{E} / V^{\prime} \mathrm{CO}_{2}$ and oxygen delivery at rest as well as during exercise. It is tempting to speculate that regulatory mechanisms are active which stimulate ventilation in order to optimise systemic oxygen delivery. Therefore, the extent of hyperventilation appears to reflect the extent of pulmonary vascular disease, cardiac dysfunction and impairment in oxygen delivery, which would directly explain the prognostic significance of hypocapnia in patients with pulmonary arterial hypertension.

\section{Study limitations}

The present study has several limitations, including its retrospective design and the fact that all data came from a single centre. Treatment strategies varied over the long study period and thus it was difficult to assess the effect of medical therapies on blood gases. Regular follow-up catheterisations

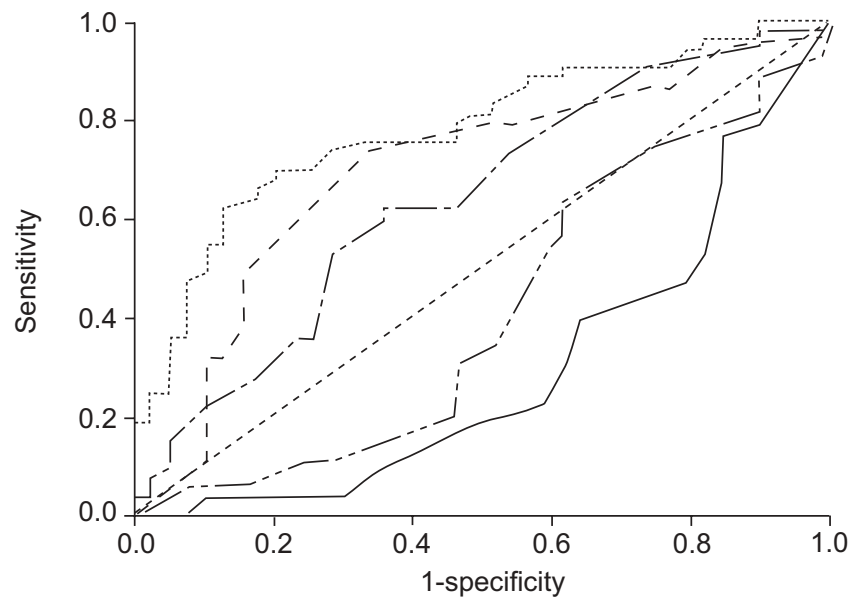

FIGURE 4. Ability of several variables to predict survival in patients with idiopathic pulmonary arterial hypertension. —_: Right atrial pressure; - - - cardiac index; - - -: carbon dioxide arterial tension; $\cdots \cdots \cdot . \cdot 6$-min walking distance; _ - - - - mean pulmonary arterial pressure; -----: no discrimination line.

were not part of the present clinical programme and exercise haemodynamics were not available. In addition, the present study relied on arterialised capillary blood gases rather than directly measuring arterial blood gases and, therefore, the present results formally apply only to blood gases obtained using this technique. However, before adopting the technique of measuring arterialised capillary blood gases, the present authors' centre performed extensive studies comparing these with arterial blood gases and excellent agreements were found (unpublished data). Thus, it is unlikely that the present findings would have been different with arterial blood gases. Finally, since only patients with IPAH were included, the present findings may not be transferable to other forms of pulmonary hypertension or to patients with confounding factors, such as restrictive or obstructive lung disease or anaemia. Despite these limitations, the relatively large sample size, the long follow-up and the fact that blood gases were routinely obtained from all patients allow the current authors to draw some meaningful and clinically important conclusions.

\section{Conclusion}

A low carbon dioxide arterial tension $(<4.25 \mathrm{kPa})$ is an independent prognostic marker in patients with idiopathic pulmonary arterial hypertension with similar predictive value for mortality than established variables, such as the 6-min walking distance or the right atrial pressure. Carbon dioxide arterial tension is easily assessable and well suited for repeated measurements, possibly making it a useful addition to the growing list of biomarkers that reflect the severity of the disease.

\section{REFERENCES}

1 Galie N, Torbicki A, Barst R, et al. Guidelines on diagnosis and treatment of pulmonary arterial hypertension. The Task Force on Diagnosis and Treatment of Pulmonary Arterial Hypertension of the European Society of Cardiology. Eur Heart J 2004; 25: 2243-2278. 
2 Rich S, Dantzker DR, Ayres SM, et al. Primary pulmonary hypertension. A national prospective study. Ann Intern Med 1987; 107: 216-223.

3 Sun XG, Hansen JE, Oudiz RJ, Wasserman K. Gas exchange detection of exercise-induced right-to-left shunt in patients with primary pulmonary hypertension. Circulation 2002; 105: 54-60.

4 Hoeper MM, Taha N, Bekjarova A, Gatzke R, Spiekerkoetter E. Bosentan treatment in patients with primary pulmonary hypertension receiving nonparenteral prostanoids. Eur Respir J 2003; 22: 330-334.

5 Hoeper MM, Markevych I, Spiekerkoetter E, Welte T, Niedermeyer J. Goal-oriented treatment and combination therapy for pulmonary arterial hypertension. Eur Respir J 2005; 26: 858-863.

6 Wensel R, Georgiadou P, Francis DP, et al. Differential contribution of dead space ventilation and low arterial $\mathrm{pCO}_{2}$ to exercise hyperpnea in patients with chronic heart failure secondary to ischemic or idiopathic dilated cardiomyopathy. Am J Cardiol 2004; 93: 318-323.

7 Metra M, Dei Cas L, Panina G, Visioli O. Exercise hyperventilation chronic congestive heart failure, and its relation to functional capacity and hemodynamics. Am J Cardiol 1992; 70: 622-628.

8 Reindl I, Wernecke KD, Opitz C, et al. Impaired ventilatory efficiency in chronic heart failure: possible role of pulmonary vasoconstriction. Am Heart J 1998; 136: 778-785.

9 Sun XG, Hansen JE, Oudiz RJ, Wasserman K. Exercise pathophysiology in patients with primary pulmonary hypertension. Circulation 2001; 104: 429-435.
10 Johnson RL Jr. Gas exchange efficiency in congestive heart failure II. Circulation 2001; 103: 916-918.

11 Wensel R, Opitz CF, Anker SD, et al. Assessment of survival in patients with primary pulmonary hypertension: importance of cardiopulmonary exercise testing. Circulation 2002; 106: 319-324.

12 Yasunobu Y, Oudiz RJ, Sun XG, Hansen JE, Wasserman K. End-tidal $\mathrm{PCO} 2$ abnormality and exercise limitation in patients with primary pulmonary hypertension. Chest 2005; 127: 1637-1646.

13 Ponikowski P, Francis DP, Piepoli MF, et al. Enhanced ventilatory response to exercise in patients with chronic heart failure and preserved exercise tolerance: marker of abnormal cardiorespiratory reflex control and predictor of poor prognosis. Circulation 2001; 103: 967-972.

14 Fanfulla F, Mortara A, Maestri R, et al. The development of hyperventilation in patients with chronic heart failure and Cheyne-Strokes respiration: a possible role of chronic hypoxia. Chest 1998; 114: 1083-1090.

15 Gitt AK, Wasserman K, Kilkowski C, et al. Exercise anaerobic threshold and ventilatory efficiency identify heart failure patients for high risk of early death. Circulation 2002; 106: 3079-3084.

16 Buller NP, Poole-Wilson PA. Mechanism of the increased ventilatory response to exercise in patients with chronic heart failure. Br Heart J 1990; 63: 281-283.

17 Chua TP, Ponikowski P, Harrington D, et al. Clinical correlates and prognostic significance of the ventilatory response to exercise in chronic heart failure. J Am Coll Cardiol 1997; 29: 1585-1590. 